\title{
The Research of Coal and Gas Outburst Warning Based on Logistic Regression and Geographic Information System
}

\author{
Bo You ${ }^{D},{ }^{1,2}$ Bo Li, ${ }^{1}$ Shi Liang Shi, ${ }^{1}$ He Qing Liu, ${ }^{1}$ Yi Lu, ${ }^{1}$ and $\mathrm{He} \mathrm{Li}^{1}$ \\ ${ }^{1}$ School of Resource, Environment and Safety Engineering, Hunan University of Science and Technology, Xiangtan, China \\ ${ }^{2}$ State Key Laboratory of Safety and Health for Metal Mines, Ma'anshan 24300, China \\ Correspondence should be addressed to Bo You; 494907336@qq.com
}

Received 23 April 2021; Revised 1 July 2021; Accepted 2 July 2021; Published 10 July 2021

Academic Editor: Feng Du

Copyright (C) 2021 Bo You et al. This is an open access article distributed under the Creative Commons Attribution License, which permits unrestricted use, distribution, and reproduction in any medium, provided the original work is properly cited.

Coal and gas outburst is one of the major disasters in the safety production of coal mine. According to the mechanism of coal and gas outburst, based on the comprehensive analysis of various influencing factors of coal and gas outburst, with the principles of selected early warning indicator, the basic information database of coal and gas outburst warning is constructed, and the information data query function is realized. The mathematical model of coal and gas outburst warning is established by the logistic regression analysis based on the gas concentration, the gas desorption index of drill cuttings, and the initial velocity of gas emission from the borehole. The multivariate information coupled warning was conducted according to the selected early warning indicator system, and the early warning level was divided with the result of early warning. The design and research of the coal and gas outburst warning system are carried out based on the geographic information system (GIS). The coal and gas outburst warning system was verified by taking the Tunliu mine of Lu'an Group as an example. The establishment of the early warning system is a new technical way to the early warning management of coal and gas outburst and can provide a guarantee for coal and gas outburst prevention.

\section{Introduction}

Coal and gas outburst is an extremely complex dynamic phenomenon in the process of coal mining [1]. Coal and gas outburst is the result of various factors, such as ground stress, coal seam gas, and physical and mechanical properties of coal $[2,3]$. A lot of research work has been conducted in mine and gas outburst prediction and warning [4-6]. The prediction of coal and gas outburst is based on the process of understanding coal and gas outburst and its influencing factors. A comprehensive hypothesis is generally accepted for the mechanism of coal and gas outburst $[7,8]$. The coal and gas outburst is controlled by the combination of ground stress, coal seam gas, and physical properties of coal $[9,10]$. The purpose of the research on the mechanism of coal and gas outburst is to predict the degree of danger and to take corresponding prevention measures $[11,12]$. Some modern mathematical theories and methods are also widely used in the prediction of coal and gas outburst, mainly including the grey theory [13], artificial neural network [14], and support vector machine algorithm [15]. So far, the prediction methods of coal and gas outburst can be divided into three categories, namely, traditional gas geological methods, emerging noncontact predictions and modern computer science techniques, and mathematical theoretical methods $[10,16]$.

Aiming at the current research and the status of coal and gas outburst prediction indicators at home and abroad, it is considered that the following aspects of the current research on predictive indicators need to be further studied: (1) the coal structure reflects the coal seam strain history and strain characteristics, which is not systematically understood for the tectonic evolution experienced by tectonic coal and the distribution law of tectonic coal, and (2) the coal structure is not mature in the prediction of coal and gas outburst. Most of them are only in qualitative analysis, but a few are quantitative studies. The issue how to identify the sensitivity of structural coal in different locations to each parameter needs to be solved. 
In the process of outburst disaster development, the influence degree of each factor is different, so the traditional single factor prediction method is difficult to meet the needs of production. There are complex nonlinear relationships among influencing factors of coal and gas outburst. Logistic and GIS analysis methods not only have strong nonlinear approximation ability but also have the function of real-time regional prediction. Therefore, the development of logistic and GIS multi-information coupling monitoring and early warning index system provides a new forecasting method for the prediction of coal and gas outburst.

\section{The Basic Information Database of Coal and Gas Outburst Warning}

According to the comprehensive hypothesis, the structural stress and gas and coal structure are the three main factors that lead to coal and gas outburst. The main argument is that coal and gas outburst is the result of a combination of ground stress and gas and coal structural properties. Except for ground pressure and gas pressure, there is no other energy source that causes outbursts in the coal seam.

The system index includes mining depth, coal seam thickness, coal seam dip angle, firmness coefficient, coal seam gas content, gas pressure, and initial velocity of gas emission. The index is established through the analysis of the influencing factors of coal and gas outburst. Then, it can select different risk assessment indicators and establish a database of coal and gas outburst characteristics according to different mining areas, different well fields, and different working faces' coal bodies, coal seams, and their gas' characteristics and disciplinarian. The system database uses Microsoft SQL as the database. SQL (Structured Query Language) is the standard language of relational databases, integrating data query, data manipulation, data definition, and data control functions [17]. The message query interface of the database of coal and gas outburst characteristics is shown in Figure 1.

\section{The Model of Coal and Gas Outburst Warning}

3.1. Warning Indexes. Under the structural stress, the composition and original structure of coal in the original coal seam change, and the structural coal with different degrees of damage is formed. The degree of coal body damage is an important indicator to measure the risk of coal and gas outburst. At the same time, the structural coal damaged by the structure stress has abnormal gas parameter characteristics. Coal and gas outburst structure's physical environment reflects the important role tectonic coal plays in coal and gas outburst. This paper analyzes the structural coal structure, coal structure characteristics, and gas parameters of the study area; determines the early warning evaluation index of coal and gas outburst; and combines the gas geological theory to predict the risk of coal and gas outburst.

The single factor of drilling cuttings gas desorption index, gas concentration, and the initial velocity of gas emission from the borehole is adopted to predict the

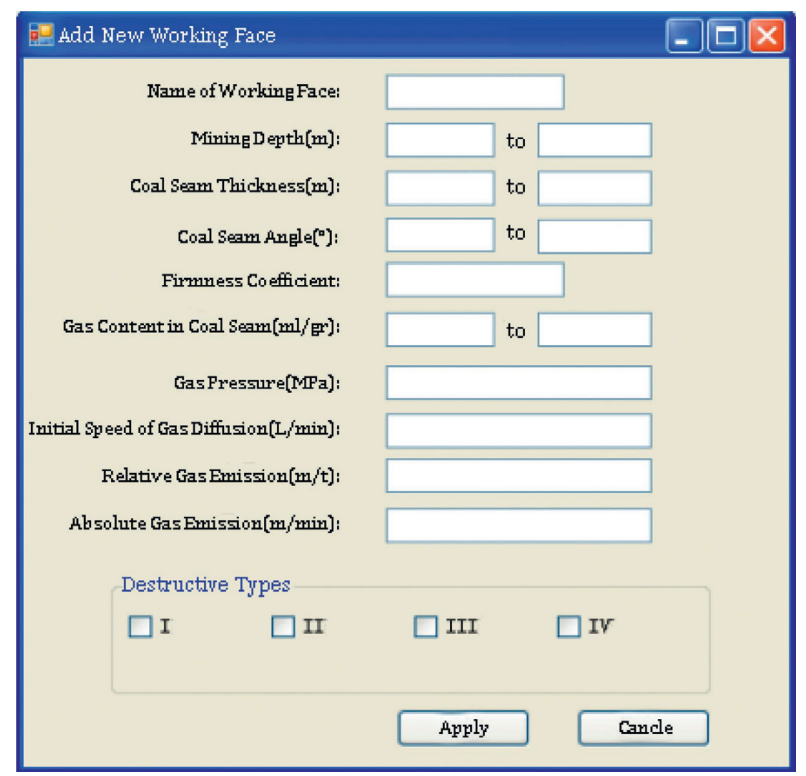

FIgURE 1: Message query interface.

outburst risk in Lu'an Tunliu mine. However, with the continuous increase of mining depth, the occurrence of the coal seam is also changing, so the single factor prediction is obviously not suitable for the prediction of outburst risk. After many years of research, it is generally believed that ground stress, coal seam gas, and mechanical properties of coal are the direct causes of outbursts. Therefore, the multivariate information coupled warning is needed to predict coal and gas outburst. The index of drilling cuttings mainly reflects the effect of ground stress and the mechanical properties of coal. Drilling cuttings gas desorption index can correctly reflect the relationship between the damage degree of coal structure and the gas content. The gas concentration can effectively reflect three aspects of ground stress, coal seam gas, and mechanical properties of coal.

The fundamental purpose to build coal and gas outburst warning is to forecast the degree of danger of coal and gas outburst. So, choosing scientific, reasonable, and effective indexes to build a complete indicator system is the basis and premise for the warning of coal and gas outburst.

(1) Gas concentration: Gas plays a vital role in the process of gestation and development of the coal and gas outburst. According to the research of modern scientists and scholars, coal and gas outburst is mainly the mechanical processes that occur when the coal body is suddenly destroyed under the coupling of coal body deformation and gas flow. The gas in the coal body has an effect on the physical and mechanical properties of coal and the response characteristics of its mechanical properties. The process of deformation and failure of coal body is dominated by the formation and expansion of internal microcracks. The coal mine safety monitoring system can monitor the gas concentration in real time, which reflects the inherent relationship among mechanical properties of coal, the coal seam gas, the ground 
stress, and so on. If gas concentration is steady and not exceeding the standard and emission keeps relatively stable, the possibility of coal and gas outburst occurrence is lower; otherwise, the possibility will increase.

(2) Drilling cuttings gas desorption index $\left(\Delta h_{2}\right)$ : Using drilling cuttings gas desorption index to predict the risk of coal and gas outburst is common in home and abroad. Experiments proved that the value of drilling cuttings gas desorption index can clearly reflect the comprehensive effect between gas content in the coal seam and destruction degree of coal body structure. The nature of coal structure, the amount of gas content and gas pressure in the coal seam, and the damage degree of coal body structure are all closely related to the characteristic value of gas desorption in the coal seam. Experiments show that the higher the failure type of coal is, the greater the desorption rate of coal will be. The amount of gas desorption of coal samples in the outburst area is much larger than that in the outburst hazard-free area. Therefore, the dangerous degree of coal seam outburst is fully reflected through the gas desorption index.

(3) Initial velocity of gas emission from borehole $(q)$ : The initial velocity of gas emission from boreholes is a comprehensive index to evaluate the risk of outburst, which reflects the relevant factors that determine the risk of outburst in the coal seam. The experimental results show that the initial velocity of gas emission can reach a higher value when the gas permeability of the test site is high. The gas emission velocity of the borehole has a certain maximum value. In most cases, the maximum value is at the last 0.5-5 mins of the survey, and the time from the end of drilling to the beginning of the measurement is usually not more than 2-3 mins. The reason that the initial velocity of gas emission increased in the initial stage is that the free gas constantly filled the measuring room and the residual gas pressure increases in the measuring room. The maximum amount of gas gushing out of the measuring room per unit time after sealing is called the initial velocity of gas emission from the borehole. Under different original gas pressure, the gas emission velocity of the borehole varies with time and has a certain relationship with the original gas pressure. The larger the original gas pressure is, the faster the initial velocity of gas emission from the borehole will be.

3.2. Warning Model. The so-called logistic regression analysis refers to the regression analysis in which the dependent variable is the second-order scoring or secondorder assessment. In coal mine safety, the occurrence of coal and gas outburst is taken as the dependent variable. Then, the dependent variable conforms to the basic characteristics of regression analysis in which the dependent variable is the second-order scoring or second-order assessment. Logistic regression analysis can be used to analyze the relationship between outburst risk occurrence probability, outburst prediction index value, and outburst omen, so as to realize the combination of outburst prediction index and outburst omen.

3.2.1. Logistic Regression Model. Logistic regression analysis is applied to analyze and interpret the relationship between a dependent variable of a name scale and more than one isometric independent variable [18]. Firstly, the biggest difference between it and multiple regression analysis is the difference in the nature of dependent variables. Because of the different nature of the dependent variables, this makes some difference in parameter estimation and hypothesis between them. In regression analysis, usually, the regression model must conform with the normal assumption. But the assumption of logistic regression analysis is that the probability distribution of the sample on the dependent variable is S-shaped, especially called logistic distribution. Secondly, in terms of parameter estimation, the regression analysis usually obtains the best estimate of the independent parameter based on the principle of minimizing the residual value through the least squares method; but the logistic regression analysis is through the maximum likelihood method, based on the principle of maximizing the probability of the number of observations of the dependent variable. Then, the best estimate of the independent parameter is obtained.

In the traditional multiple regression, since the dependent variable $Y$ is a continuous variable, the conditional average to calculate $Y$ is equal to a certain value as follows:

$$
E(Y \mid x)=\beta_{0}+\sum_{i=1}^{p} \beta_{i} X_{i}
$$

In formula (1), $E(Y \mid x)$ means that $Y$ is equal to the expected value of the conditional average of a certain value, which is a linear equation of the $x$ variables. But when the dependent variable is a dichotomous variable, the expected value will fall between 0 and 1 , as $0 \leq E(Y \mid x) \leq 1$. At this point, if we calculate $E(Y \mid x)$, respectively, based on the measured values of the sample in the independent variable $X$ and set the value of $E(Y \mid x)$ at plane coordinate, it will be found that the probability distribution is no longer a straight line, but similar to S-type. And the equation of this curve is

$$
f(x)=\frac{1}{1+e^{-z}}
$$

From equation (2), when the value of $z$ approaches $-\infty, f$ $(z)$ approaches 0 ; when the value of $z$ approaches $\infty, f(z)$ approaches 1 . And $z$ is equal to

$$
z=\beta_{0}+\sum_{i=1}^{p} \beta_{i} X_{i}=\beta_{0}+\beta_{1} X_{1}+\beta_{2} X_{2}+\cdots+\beta_{p} X_{p}
$$

The function $f(z)$ formed by the expected value of the conditional mean of the above-mentioned binary variable is called a logistic function, and the dependent variable is no longer a variable of equal distance or more, so $E(Y \mid x)$ is 
called a conditional probability. For convenience, sometimes $P(y)$ can be written as

$$
P(y)=\frac{1}{1+e^{-z}}=\frac{1}{1+e^{-\left(\beta+\sum \beta_{i} X_{i}\right)}} .
$$

According to the success probability of formula (4) $P(y)$, the conditional probability of failure of a binary name variable is

$$
1-P(y)=1-\frac{1}{1+e^{-\left(\beta+\sum \beta_{i} X_{i}\right)}}=\frac{e^{-\left(\beta+\sum \beta_{i} X_{i}\right)}}{1+e^{-\left(\beta+\sum \beta_{i} X_{i}\right)}} .
$$

In order to perform logistic regression analysis, we must convert the logistic function into a linear property, since the logistic function is not a linear function. To convert, we must first calculate the odds (odd), and the calculation of the odds value is

$$
\operatorname{Odd}=\frac{P(y)}{1-P(y)}=\frac{1 /\left(1+e^{-\left(\beta+\sum \beta_{i} X_{i}\right)}\right)}{e^{-\left(\beta+\sum \beta_{i} X_{i}\right)} /\left(1+e^{-\left(\beta+\sum \beta_{i} X_{i}\right)}\right)}=e^{\left(\beta+\sum \beta_{i} X_{i}\right)} .
$$

From the value of formula (6), we know that the probability of success represents the ratio of the probability of occurrence (success) of an event to the probability of nonoccurrence (failure); that is to say, the probability of occurrence of an event is several times that of nonoccurrence.

Formula (6) shows that the odds are still not linear, so it is necessary to further convert the natural logarithm of the odds; that is,

$$
\operatorname{In}(\text { Odd })=\frac{P(y)}{1-P(y)}=\beta_{0}+\sum_{i=1}^{p} \beta_{i} X_{i}=\beta_{0}+\beta_{1} X_{1}+\beta_{2} X_{2}+\cdots+\beta_{p} X_{p} .
$$

It can be known from formula (7) that when the odds are taken as the natural logarithm, it becomes a linear equation, and this process is a logit transformation. When the logit conversion is completed, the researcher can use the maximum likelihood for parameter estimation to further explain the relationship between variables and make predictions.

3.2.2. The Steps of Logistic Regression Analysis. For a binary nominal variable, we usually use $p$ to represent the probability of success and $1-p$ to represent the probability of failure. So for the binary dependent variable $Y$, the measurement of the observation (the conditional probability of being equal to 1 or 0 ) is

$$
P\left(Y=y_{i}\right)=p^{y_{i}}(1-p)^{1-y_{i}}
$$

Then, the maximum likelihood method is used to estimate the parameters of the logistic regression analysis. First, the likelihood ratio function $L$ of $N$ independent observations is calculated. The calculation of $L$ is

$$
L=\prod_{i=1}^{N} p^{y_{i}}(1-p)^{1-y_{i}}=\prod_{i-1}^{N}\left(\frac{1}{1+e^{-\left(\beta+\sum \beta_{i} X_{i}\right)}}\right)^{y_{i}}\left(\frac{e^{-\left(\beta+\sum \beta_{i} X_{i}\right)}}{1+e^{-\left(\beta+\sum \beta_{i} X_{i}\right)}}\right)^{1-y_{i}} .
$$

Take the natural logarithm to the formula likelihood ratio function, differentiate the estimated parameters $\beta$ separately, and make the obtained differential equation equal to zero. Thus, the parameter estimates of the logistic regression analysis can be obtained. The likelihood ratio function takes the natural logarithm as follows:

$$
\operatorname{In} L=\sum_{i=1}^{N} y_{i} \operatorname{In}\left(\frac{1}{1+e^{-\left(\beta+\sum \beta_{i} X_{i}\right)}}\right)+\sum_{i=1}^{N}\left(1-y_{i}\right) \operatorname{In}\left(\frac{e^{-\left(\beta+\sum \beta_{i} X_{i}\right)}}{1+e^{-\left(\beta+\sum \beta_{i} X_{i}\right)}}\right) \text {. }
$$

3.3. Engineering of Data Processing. Firstly, the gas concentration, the analytic index $\Delta h_{2}$, and the initial velocity $q$ of drilling gas emission value are defined as numerical variables, and the data precision is two decimal places after taking the decimal point. Define whether there is an outburst risk dependent variable as a character variable and input the data from the prediction table into the database at once.
Secondly, the binary logistic is selected in SPSS for regression analysis.

The value of independent parameter estimation and significance test results of the logistic regression model are output by SPSS. The second column in the report is the coefficient value of the independent variable, the third column is the standard error of the coefficient estimation, 
the fourth column is the Wald significance test value of the coefficient, the fifth column is the degree of freedom, the sixth column is the significant level, the seventh column is the occurrence rate of independent variables, and the last two columns are the estimated values of the $95 \%$ confidence interval of the occurrence ratio.

Based on the variable coefficients in the equation listed in Table 1, the probability of risk occurrence can be written in the form of a logistic function as follows:

$$
P=\frac{1}{1+\exp \left[-\sum b_{i} x_{i}\right]}=\frac{1}{1+\exp \left[-\left(5.078 x_{1}+0.41 x_{2}+11.63 x_{3}-104.728\right)\right]} .
$$

In formula (11), $x_{1}$ is gas concentration, $x_{2}$ is gas analytical strength, and $x_{3}$ is initial velocity of gas emission for the borehole.

The closer the strain variable $P$ is to 1 , the higher the outburst risk is, and the closer it is to 0 , the lower the outburst risk is.

The logistic regression model was used to treat the test data for prediction, and the prediction results are shown in Table 2.

The results of the logistic regression prediction model were compared with the data recorded in the production process of the experimental mine, and the comparison results showed that the predicted results were consistent with the situation encountered in actual production, which indicated that the logistic regression prediction model was feasible. Different mines can establish their own prediction indexes according to the actual situation and establish their own logistic regression prediction model.

\section{Construction of Warning System for Coal and Gas Outburst under GIS Environment}

4.1. Data Fusion of Early Warning Indicators. The causal factors of coal and gas outburst are not single but the result of the combined effects of various factors. Therefore, it is necessary to use a comprehensive index of various indicators affecting the risk of coal and gas outburst to reflect the dangerous state of coal and gas outburst. Due to the multisource of data sources for these reasons, effective means are needed to explain and describe the data from different sources, and the multi-information data fusion technology provides a feasible solution for this [19]. The relationship between each index and outburst factors is shown in Figure 2.

The relationship between each warning index and outburst risk is not simply superimposed. Through the analysis of each index, the form of fault tree can be adopted, and the logical relationship between each index can be expressed. If the prediction index exceeds the critical value, the value will be assigned to 1 ; otherwise, the value will be 0 , so whether the working face has outburst danger or not can be calculated by Boolean algebra. When the calculation is 1 , it shows that there is outburst risk; otherwise, there is no outburst risk.

4.2. Warning System Based on Multi-Information. Coal and gas outburst warning is the prediction and monitoring of coal and gas outburst based on the obtained information under the normal production conditions of coal mines and makes early warning of the degree of near-negative qualitative change of the system operation. The main function of the coal and gas outburst warning system is to use the relevant information and timely data obtained through monitoring and inspecting to store, process, and identify the information data. According to the conditions of the mine, the appropriate early warning indicators are selected to complete the simulation of the early warning model, and the early warning results are calculated. According to the early warning criteria, the early warning evaluation method is selected, the evaluation results are given, the state of the danger level is determined, and the prevention and control measures are taken; therefore, through the establishment and realization of the coal and gas outburst warning system, the ultimate objectives are as follows:

(1) The early warning system accurately diagnoses and evaluates the dangerous state of coal and gas outburst in the coal mining process by extracting the required information.

(2) To research coal and gas outburst warning indicators, using SPSS statistical software to simulate information data, construct mathematical equations, and conduct coal and gas outburst multi-information coupling early warning: this system is used to carry out early warning research of coal and gas outburst danger in test mine. According to the early warning results, the warning level is divided.

(3) Aiming at the hierarchical management mode of coal and gas outburst danger status, an early warning signal output method based on ArcGIS is proposed.

The multi-information coupling warning principle is shown in Figure 3.

According to the designing principles and requirements of the coal and gas outburst warning system, combined with the characteristics of GIS and logistic regression analysis, a warning scheme for coal and gas outburst is proposed. In the coal and gas outburst working surface warning system, it is based on the coal mine gas geology to determine the region's coal and gas outburst warning indicators through the analysis of the physical properties of the coal seam, gas, and ground stress, three major factors, and then do treatments and quantization for each indicator, establishing the mathematical model of coal and gas outburst warning on GIS. Finally, the distribution of gas outburst hazard level in this area is obtained according to the classification of 
TABLE 1: Variables in the equation.

\begin{tabular}{|c|c|c|c|c|c|c|c|c|}
\hline & \multirow{2}{*}{$B$} & \multirow{2}{*}{ SE } & \multirow{2}{*}{ Wald } & \multirow{2}{*}{$\mathrm{d} f$} & \multirow{2}{*}{ Sig. } & \multirow{2}{*}{ Exp. $(B)$} & \multicolumn{2}{|c|}{ 95\% CI for Exp. $(B)$} \\
\hline & & & & & & & Lower & Upper \\
\hline Gas concentration & 5.078 & 1.442 & 0.003 & 1 & 1.000 & 1.417 & 0.000 & \multirow{4}{*}{$5.34 E 13$} \\
\hline Gas analytical strength & 0.410 & 1.245 & 0.025 & 1 & 0.998 & 1.506 & 0.000 & \\
\hline Initial velocity of gas emission from borehole & 11.630 & 1.865 & 0.016 & 1 & 0.999 & 2.534 & 0.000 & \\
\hline Constant & -104.728 & 1.123 & 0.009 & 1 & 0.996 & 0.008 & & \\
\hline
\end{tabular}

TABLE 2: Discriminant results of samples to be tested.

\begin{tabular}{lcccc}
\hline Gas concentration & $\begin{array}{c}\text { Gas analytical strength } \\
\Delta h_{2}(\mathrm{~Pa})\end{array}$ & $\begin{array}{c}\text { Initial velocity of gas emission } \\
\text { from borehole } q(\mathrm{~L} / \mathrm{min})\end{array}$ & Predicted results & The actual situation \\
\hline 1.32 & 180 & 3.5 & 0.99 & Outburst \\
0.80 & 150 & 2.0 & $1.23 \times 10^{-7}$ & No outburst \\
1.30 & 120 & 2.5 & $2.39 \times 10^{-9}$ & No outburst \\
\hline
\end{tabular}

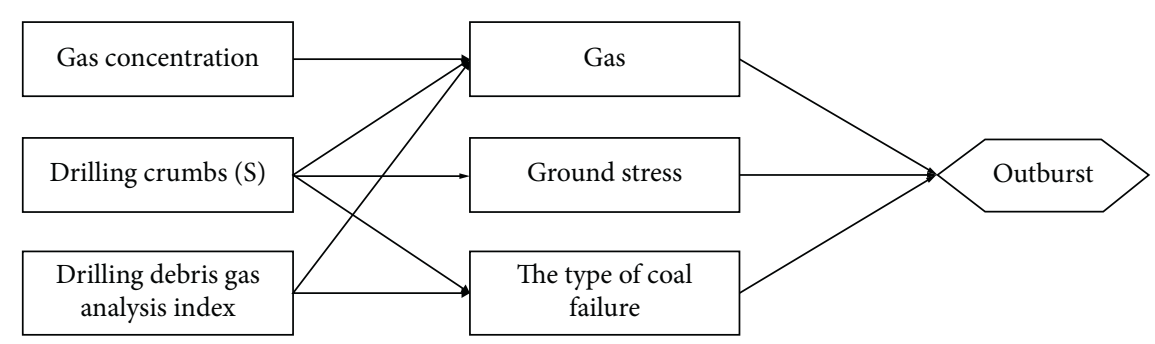

FIgURE 2: Schematic diagram of the relationship between each index and prominent factors.

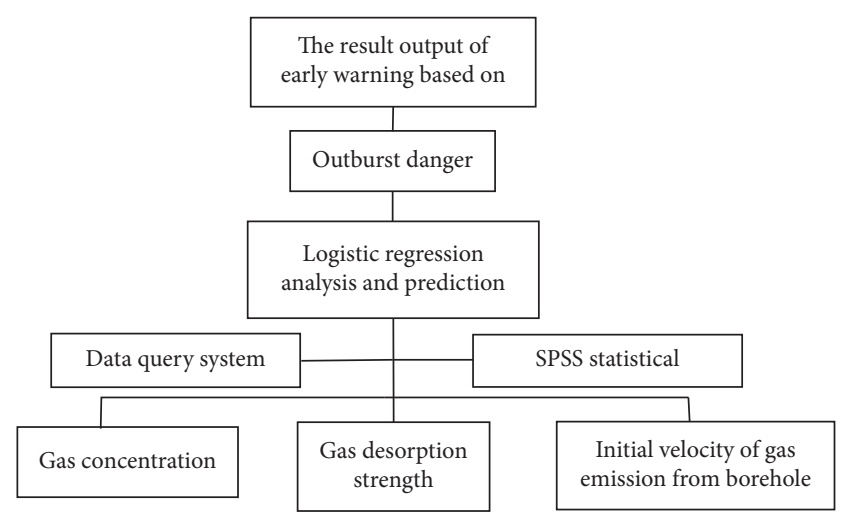

FIGURE 3: Schematic diagram of multi-information coupling warning principle.

warning. In the real-time warning system of coal and gas outburst working face, the system mainly judges whether there is gas outburst danger by extracting the gas concentration, drilling cuttings gas desorption index $\left(\Delta h_{2}\right)$, initial velocity of gas emission from borehole $(q)$, and then using the logistic regression analysis to dispose. The warning result is finally obtained as shown in Figure 4.

4.3. The Output of Warning Signal. The geographic information system (GIS) is an emerging edge discipline integrating computer technology, geoscience theory, space science, and information management technology [20]. It

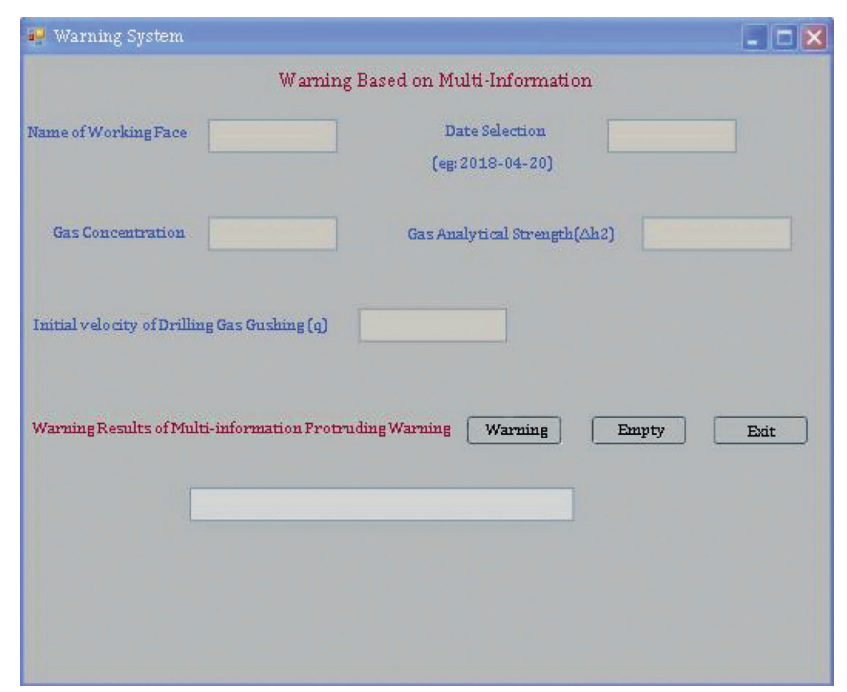

FIGURE 4: Interface of multi-information coupling warning system for coal and gas outburst.

can not only store, analyze, and express the attribute information of various objects in the real world but also deal with its spatial positioning features, combine spatial data and attribute information, and provide data query, retrieval, and analysis functions visually and intuitively. ArcGIS can finish every GIS task from simple to complex, including mapping, data management, geographic analysis, data editing and geoprocessing, spatial graphics, relational databases, 
TABle 3: Coal and gas outburst hazard classification.

\begin{tabular}{|c|c|c|c|}
\hline The warning level & $\begin{array}{l}\text { The description of } \\
\text { outburst risk }\end{array}$ & $\begin{array}{l}\text { Alarm limit and } \\
\text { alarm interval }\end{array}$ & Hierarchical management and precontrol strategy \\
\hline $\begin{array}{l}\text { (i) Red (serious } \\
\text { alarm) }\end{array}$ & Serious outburst risk & $\geq 75 \%$ & $\begin{array}{c}\text { Group company management: company should take immediate } \\
\text { measures, even stop production and rectification, and continue to work } \\
\text { after the danger is eliminated }\end{array}$ \\
\hline $\begin{array}{l}\text { (ii) Orange } \\
\text { (medium alarm) }\end{array}$ & General outburst risk & {$[50 \%, 75 \%]$} & $\begin{array}{l}\text { Coal mine department management: department should immediately } \\
\text { take measures to reduce the possibility of coal and gas outburst within the } \\
\text { specified time and then resume normal production }\end{array}$ \\
\hline $\begin{array}{l}\text { (iii) Yellow (light } \\
\text { alarm) }\end{array}$ & Weak outburst risk & {$[25 \%, 50 \%]$} & $\begin{array}{l}\text { District management: accidents have a development trend, should be } \\
\text { highly vigilant, and take measures when necessary to reduce the risk of } \\
\text { coal and gas outburst }\end{array}$ \\
\hline $\begin{array}{l}\text { (iv) Green (no } \\
\text { alarm) }\end{array}$ & No outburst risk & $<25 \%$ & Safety in production \\
\hline
\end{tabular}

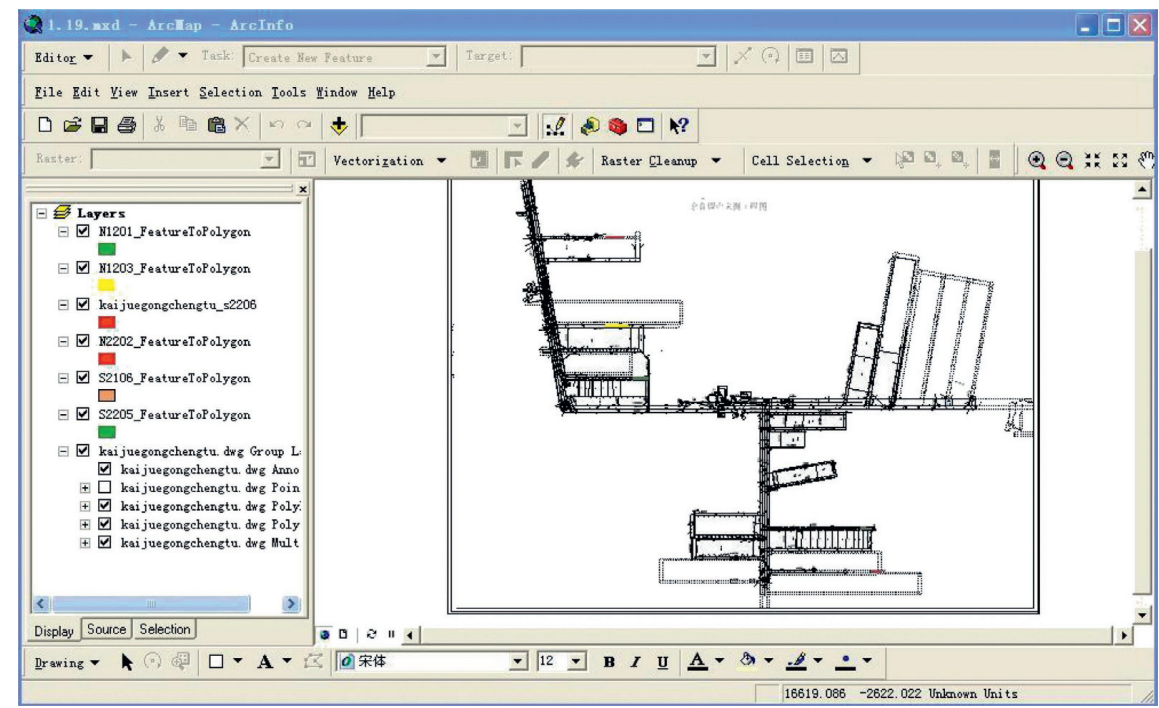

FIGURE 5: The early warning result of working face in mine.

statistical graphics, spatial analysis, network communication, object-oriented programming, support for communication between applications, and provide the interface for other applications. It relies on the operating platform of Windows and uses various resources of Windows to have powerful features and potential.

The coal and gas outburst warning system is a disaster accident decision-making system, and the accuracy of the results directly affects the reliability of the entire system. This paper adopts the internationally accepted green, yellow, orange, and red as the warning color to indicate the danger of coal and gas outburst's four status: no alarm, light alarm, middle alarm, and heavy alarm. According to the selected early warning index system and quantification method of coal and gas outburst, the early warning comprehensive index of coal and gas outburst working face is obtained through the early warning model. At the same time, according to the provisions of "Controlling Coal and Gas Outburst Rules," the early warning area of mine face is divided into 4 levels, as shown in Table 3.

By using the ArcGIS technology platform, the mine engineering drawing is visualized, the corresponding prewarning color signal is output, the basic data information of mine is displayed, and the visualization is realized. The organic combination of ArcGIS and logistic regression analysis is realized, which provides a new method and technology for coal and gas outburst warning.

Taking the Tunliu coal mine of Lu'an Group as an example, according to the model of logistic regression analysis and prediction, the multi-information coupled warning system is used to substitute the collected warning indicators to obtain the warning results of coal and gas outburst to obtain the warning results of each working face. The warning results of each working face will be updated on the work surface area automatically, and the area warning result will be displayed on the view, which is convenient for management and operation, as shown in Figure 5.

\section{Conclusion}

(1) Through the analysis of the influencing factors of coal and gas outburst, the outburst characteristic parameters are selected, and the basic information database of coal and gas outburst warning is 
established by Microsoft SQL to inquire the characteristic parameter data of coal and gas outburst conveniently.

(2) The gas concentration, the gas desorption index of drill cuttings, and the initial velocity of borehole gas emission are selected as the warning index system. The logistic regression warning model of coal and gas outburst is preliminarily fitted by SPSS software, and the sensitivity of its outburst prediction is analyzed and improved. It highlights the accuracy of prediction and better realizes the warning of coal and gas outburst.

(3) Logistic regression analysis and ArcGIS were organically combined to divide the warning grade of coal and gas outburst and output the corresponding warning grade signals. The coupling warning system of multiple information of coal and gas outburst is constructed. The visual warning function of warning of coal and gas outburst is realized. It has important guiding significance for preventing coal and gas outburst.

\section{Data Availability}

The data used to support the findings of this study are available from the corresponding author upon request.

\section{Conflicts of Interest}

The authors declare that they have no conflicts of interest.

\section{Acknowledgments}

This project was supported by the State Key Laboratory of Safety and Health for Metal Mines (2020-JSKSSYS-03).

\section{References}

[1] X. R. Luo, F. Yang, Y. T. Kang, and A. Zhang, "Research on real-time alarm theory of delayed coal and gas outburst," Journal of China University of Mininge Technology, vol. 37, no. 2, pp. 163-166, 2008.

[2] Z. X. Zhang, G.-F. Liu, R.-S. Liu, and J. Zhang, "Regional forecast of coal and gas burst based on fuzzy pattern recognition," Journal of China Coal Society, vol. 32, no. 6, pp. 592-595, 2007.

[3] B. F. Yu, Technical Manual for Coal Mine Gas Disaster Prevention and Utilization, China Coal Industry Publishing House, Beijing, China, 2005.

[4] H. Liu, B. Lin, J. Mou, and W. Yang, "Mechanical evolution mechanism of coal and gas outburst," Rock Mechanics and Rock Engineering, vol. 52, no. 5, pp. 1591-1597, 2019.

[5] G. Dong, X. Liang, and Q. Wang, "A new method for predicting coal and gas outbursts," Shock and Vibration, vol. 2020, Article ID 8867476, 10 pages, 2020.

[6] C. Zhang, E. Wang, J. Xu, and S. Peng, "A new method for coal and gas outburst prediction and prevention based on the fragmentation of ejected coal," Fuel, vol. 287, Article ID 119493, 2021.

[7] L. Qiu, Z. Li, E. Wang et al., "Characteristics and precursor information of electromagnetic signals of mining-induced coal and gas outburst," Journal of Loss Prevention in the Process Industries, vol. 54, pp. 206-215, 2018.

[8] C. Fan, S. Li, M. Luo, W. Du, and Z. Yang, "Coal and gas outburst dynamic system," International Journal of Mining Science and Technology, vol. 27, no. 1, pp. 49-55, 2017.

[9] Y.-k. Ma, B.-s. Nie, X.-q. He, X.-c. Li, J.-q. Meng, and D.-z. Song, "Mechanism investigation on coal and gas outburst: an overview," International Journal of Minerals, Metallurgy and Materials, vol. 27, no. 7, pp. 872-887, 2020.

[10] K. Jin, Y. Cheng, T. Ren et al., "Experimental investigation on the formation and transport mechanism of outburst coal-gas flow: Implications for the role of gas desorption in the development stage of outburst," International Journal of Coal Geology, vol. 194, pp. 45-58, 2018.

[11] D. Yang, Y. Chen, J. Tang et al., "Experimental research into the relationship between initial gas release and coal-gas outbursts," Journal of Natural Gas Science and Engineering, vol. 50, pp. 157-165, 2018.

[12] Y. Liang, J. Zhang, L. Wang, H. Luo, and T. Ren, "Forecasting spontaneous combustion of coal in underground coal mines by index gases: a review," Journal of Loss Prevention in the Process Industries, vol. 57, pp. 208-222, 2019.

[13] B. Liang, B. Qin, W.-J. Sun, S.-Y. Wang, and Y.-S. Dan, “The application of intelligent weighting grey target decision model in the assessment of coal-gas outburst," Journal of China Coal Society, vol. 38, pp. 1611-1615, 2013.

[14] X. He, W. Chen, B. Nie, and M. Zhang, "Classification technique for danger classes of coal and gas outburst in deep coal mines," Safety Science, vol. 48, no. 2, pp. 173-178, 2010.

[15] J.-e. Liu, F.-1. Zeng, and Z.-1. Guo, "Gas outburst risk analysis based on pattern recognition of RSSVM model," in Proceedings of the 2012 International Workshop on Information and Electronics Engineering, vol. 29, pp. 170-173, Harbin, China, 2012.

[16] X. S. Zhao, Q. T. Hu, and X. L. Ning, "Research on comprehensive early-warning technology of coal and gas outburst," Procedia Engineering, vol. 26, pp. 2376-2382, 2011.

[17] S. Wang and S. X. Sa, Introduction to Database System, Higher Education Press, Beijing, China, 2006.

[18] J. B. Wang, Multivariate Analysis: Statistical Software and Data Analysis, Peking University Press, Beijing, China, 2007.

[19] D. X. Jing and Y. Z. Yang, Mine Critical Hazard Identification and Evaluation Level Warning Technology, Metallurgical Industry Press, Beijing, China, 2008.

[20] H. H. Sheng, S. Li, and Q. J. Wang, "Application of GIS to establish coal and gas outburst area prediction management system," Safety in Coal Mines, vol. 32, no. 11, pp. 40-42, 2001. 